Chapter 4

\title{
Cerebral Palsy and Accessible Housing
}

\author{
Emira Švraka \\ Additional information is available at the end of the chapter \\ http://dx.doi.org/10.5772/56983
}

\section{Introduction}

Healthcare systems in transition countries must adapt to the many changes occurring in society as a whole. This is a very serious process requiring reforms that will significantly change the management and organization of healthcare at all levels. Bosnia and Herzegovina has suffered large scale destruction during the war (1992-1995), and all the medical capacities in the country sustained significant damage. The causes of demographic changes in transition countries include: the growth of urban populations, expansion of education, the modernization of society, the disintegration of the family, medical advances, increased income, decreased fertility and increased mortality (Loga S, 2011).

Community Based Rehabilitation (CBR) is strategy for rehabilitation, equal possibilities and social integration of all persons with disabilities. CBR program is implementing with joint effort of persons with disabilities, their families, community and related health, educational and social institutions. Before the 1992, medical rehabilitation in Bosnia and Herzegovina had been provided at the level of institutions, usually after the hospital or ambulant treatments. Model of Community Based Rehabilitation (CBR), which practically tested in all parts of Bosnia and Herzegovina, suggests numerous advantages when compared to the previous period, until 1992.

There is large number of health and educational institutions in the Canton of Sarajevo which are working on re/habilitation and education of children and adolescents with disabilities, but there isn't unique database about the people with disabilities, as well as with cerebral palsy. Lack of unique database indicates poor network among the institutions and Associations in the Canton of Sarajevo.

A number of issues arise from the study "Family Quality of Life: Adult School Children with Intellectual Disabilities". Four of the seemingly most important are: lack of organized community services for adults after they leave school; lack of a cantonal, state, or federal 
registration program that would improve coordination of health and social services and link to the European Register; necessity of conducting continuous education for the teaching staff at schools regarding effective curricula, for parents, and for health professionals; and the possibility of developing occupational and physical therapy programs for children, adolescent, and adults. The degree to which improvements such as these might affect family quality of life also needs to be examined in future study (Švraka E, Loga S, Brown I, 2011).

The goals of education and rehabilitation in Bosnia and Herzegovina, similar to most other countries of the world, are to work toward community inclusion, acceptance of diversity, optimal physical and mental health, and personal and social well-being. The focus on family quality of life is a step toward understanding how we can move closer to achieving these goals (Švraka, Loga, Brown, 2011).

The fact that concerns the most in the South-Eastern Europe is that many people with disabilities are isolated in their homes. One reason for this isolation is huge barriers that must face when they try to go out of their homes. Common premises, such as elevators, corridors and passages often are inaccessible. This only reinforces the fact that most laws on accessibility applies only to public buildings, so that investors who invest in private buildings can go unpunished for not fulfilling these regulations (Sestranetz, Adams, 2006).

\subsection{Cerebral palsy}

Cerebral palsy $(\mathrm{CP})$ is characterized by nonprogressive abnormalities in the developing brain that create a cascade of neurologic, motor and postural deficit in the developing child. Cognitive, sensory and psychosocial deficits often compound motor impairments and subsequent functioning. Characteristically, the child with CP shows impaired ability to maintain normal posture because of a lack of muscle coactivation and the development of abnormal movement compensations. These compensatory patterns develop in certain muscle groups to maintain upright postures and move against gravity. Hyperactive responses to tactile, visual or auditory stimuli may result in fluctuations of muscle tone that often adversely affect postural control and further diminish coordinated responses in everyday activities (Rogers, Gordon, Schanzenbacher, Case-Smith, 2001).

Cerebral palsy (CP) occurs at present in about 2,2 per 1000 live born children in Sweden. Epilepsy occurs in $15 \%$ to more than $60 \%$ of children with $\mathrm{CP}$, depending on the type of $\mathrm{CP}$ and the origin of the series, compared with $0,5 \%$ in the general population (Carlsson, Hagberg, Olsson, 2003).

According to the time of influence, causes of cerebral palsy can be divided to prenatal (from conception until beginning of the delivery), perinatal (beginning of the delivery until age of 28 days) and postnatal (from $29^{\text {th }}$ day of age until two years of age). The majority of international studies indicates that the prevalence of the cerebral palsy is about 2-2,5 cases per 1000 born, although there are some reports about lower and higher prevalence rates (Nordmark, Hagglund, Lagergren, 2001). 
Evidences indicated that $70-80 \%$ of cerebral palsy is caused by the prenatal factors and that the birth asphyxia has a relatively minor role with the less than $10 \%$ (Jacobsson \& Hagberg, 2004).

Early diagnosis of CP symptoms followed with early intervention is crucial, as soon as possible.

With the rising incidence of $\mathrm{CP}$ in time, the distribution over the subtypes changed: fewer cases with diplegia and more with hemiplegic. The motor impairments of $C P$, in especially the spastic types, lead to other impairments of the musculoskeletal system; for example; among children and adolescents with quadriplegic $\mathrm{CP}, 75 \%$ have hip luxations, $73 \%$ contractures, and $72 \%$ scoliosis (Odding, Roebroeck \& Stam, 2006).

About $40 \%$ of children with hemiplegic CP have normal cognitive abilities, while children and adolescents with tetraplegic CP are generally severely intellectually impaired (Odding, Roebroeck \& Stam, 2006).

$\mathrm{CP}$ associated with epilepsy is far more frequently accompanied by intellectual disability than CP without epilepsy. Similarly, the combination of CP and intellectual disability is reported to be associated with a high risk of developing epilepsy (Carlsson, Hagberg \& Olsson, 2003).

Many children with more severe spastic CP experience communication problems due to disturbed neuromuscular control of speech mechanism, i. e, dysarthria, that diminish the ability of the child to speak intelligible. However, substantial dysarthria are most often seen in children with severe $\mathrm{CP}$ and intellectual disability, while most children with mild or moderate $\mathrm{CP}$ and average cognitive level of functioning have normal or near-normal expressive language and articulation skills (Bottcher, 2010).

In the study of the influence of prenatal etiological factors on learning disabilities of children and adolescents with cerebral palsy in the Canton of Sarajevo, of all sample, 31 (38,75\%) children with CP used nonverbal and sign communication, and $49(61,25 \%)$ children used verbal communication (i.e. speech).

Depending of the study, the prevalence of visuomotor and perceptual problems among children with spastic CP varies from 39\% to $100 \%$ (Stiers \& Vanderkelen, 2002)

Professionals and parents need to be aware that children with cerebral palsy are at higher risk of psychological problems than their non-disabled peers and this may be attributable to problems in adjustment to their adverse circumstances as well as having an organic basis. Attention should be paid to the effective management of pain, particularly in children unable to self-report for whom a reliable instrument for assessing pain now exists. The difficulties most commonly reported here were peer problems; as these may have implications for later psychological adjustment, follow up work into adolescence and beyond will be important. It may be that for many children with cerebral palsy and their families, chronic psychological problems will have a greater impact than the physical impairments and this possibility also needs to be investigated in longitudinal studies (Parkes, White-Koning, Dickinson, Thyen, Arnaud, Beckung \& all, 2008). 


\subsection{Occupational therapy for persons with cerebral palsy in the Canton of Sarajevo}

The research was conducted through Project: „Occupational therapy for persons with cerebral palsy", in homes of participants. The aim was to determine accessible housing for persons with cerebral palsy.

The client was Association of persons with cerebral palsy in the Canton of Sarajevo. The Association includes 315 members. Of that number, 123 (47,13\%) are children and adolescents, age 4 up to 20 years, and 138 (52,87\%) are adults.

Sample was consisted of 30 members of the Association of persons with cerebral palsy of the Canton of Sarajevo, age from 4 up to 53: 8 children (4-11 years), 14 adolescents (12-20 years), and 8 adults (21-53 years); 14 male (46,67\%) and 16 (53,33\%) female.

Nine participants had private houses, and 21 were living in flats.

The principal measure used was the Environmental Assessment - Home assessment form. The first part should deal with accessibility of the dwelling's exterior, and the second half should be concerned with an assessment of the home's interior. During the On-Site visit a tape measure and home assessment form are tools (Schmitz, 1988), translated and modified by the author (Švraka, 2007).

The part about accessibility of the dwelling's exterior is made of 36 items: type of home, entrances to building or home, approach to apartment or living area (hallway, steps, door, and elevator). "Inside home" part consists of bedroom, bathroom, living room area, dining room, kitchen, laundry, cleaning, emergency and few other items.

The study was approved by parents of children with $\mathrm{CP}$, or adults with $\mathrm{CP}$, and president of the Association of persons with cerebral palsy in the Canton of Sarajevo. Before starting the data collection, the research aim and Environmental Assessment - Home assessment form were explained to parents and they agree to participate by signing consent.

Ideally, the physical and occupational therapists should accompany the patient on the home visit. They assume shared responsibility for assessing the patient's functional level at home. Depending of the specific needs of the patient and/or family, a speech therapist, social worker, or nurse also may be included on the home visit (Shmitz, 1988).

Research was conducted during 3 months period trough home visits to clients. Basic inclusion criteria were:

1. Association members with severe motor disability,

2. Lower community engagement or majority of clients are not involved in some form of institution, continuous forms of education and/or re/habilitation.

Students of Department of physiotherapy, at Faculty of Health Studies in Sarajevo, who have completed their course of studies, apply the Environment assessment - Home assessment form in patient's home as part of practical education, in an environment that does not have the occupational therapy program. Supervision was performed by assistant professor of Faculty of Health Studies. Based on the initial assessment of the patient in the house/ On-site 
assessment, individual therapeutic programs/interventions were made in order to improve occupational performance.

1. Interventions which changed requirements of occupation was bringing large gymnastic ball in the home of all 30 patients.

2. Interventions that want to affect the environment, followed after the evaluation. In cooperation with the police and local community, students were working on improvement of accessibility: free parking places in front of the building, entrance ramps, accessible elevators.

3. Interventions that want to improve the ability of the person was the education in certain exercises for the improvement and preservation of posture, balance, coordination, increase the mobility and prevention of deformities deterioration, which influenced the personal competencies, i.e. skills related to motor performance, sensor abilities, cognitive ability and general health condition.

The Association of persons with cerebral palsy in the Canton of Sarajevo is member of Cerebral Palsy Association of Federation of Bosnia and Herzegovina which was established at 17. October of 2011. That day was announced as Day of persons with cerebral palsy of Federation of Bosnia and Herzegovina (FB\&H). Cerebral Palsy Association members include five Associations of persons with cerebral palsy of FB\&H, from five towns/Cantons: Sarajevo, Goražde, Zenica, Široki Brijeg and Sapna.

People with CP can lead active lives and make a valuable contribution to society. Art workshop of the Association of persons with cerebral palsy in the Canton of Sarajevo consists of 9 female members, 7 with CP and 2 with paraplegia. Middle age is 37,7 years; two youngest members are 27 years old, and oldest one is 58 year old. Five members use wheelchairs (3 with $\mathrm{CP}$ and 2 with paraplegia), one cane, and three of them are walking independently. It is necessary to reduce the numbers of sheltered workshops, and develop supported employment and self-employment, in other to reduce segregation of persons with disabilities and give support to social inclusion.

\subsection{Assistive technology}

Assistive technology (AT) is an umbrella term for a wide range of products. A commonly accepted definition is "any item, piece of equipment or product system whether acquired commercially off the shelf, modified or customized that is used to increase, maintain or improve functional capabilities of individuals with disabilities" (US Statute, 1988). Therefore in terms of devices or equipment it includes from walking sticks to environmental control systems (ECS), or simple dressing aids to communication aids (Cowan \& Wintergold, 2007).

Assistive devices include ortho-prosthetic devices, wheel chairs, walking aids, technical aids and adapted controls for cars. Adequate assistive devices are often financially inaccessible to many users because of their high cost despite the fact that they should be covered by social and insurance schemes. Under the current system, most assistive devices are covered only partially by the state and require user co-payments, which can be exorbitant in cost. Within 
the socialist system, assistive devices were generally provided for free within the public health care system. This is a crucial issue in South East Europe as one of the largest barriers to accessing assistive devices is financial. Ortho-prosthetic devices are partially subsidized by the state and in most countries, co-payments have been set up but the financial burden is still heavy, especially for mid to low-income households. For example, in Bosnia and Herzegovina, co-payments can range from 10-50\%, which can range from EUR 100-1,000 depending on the device. In the UN administered province of Kosovo there is an absence of a health care financing system so patients must pay the full price for their wheelchairs or other devices (Handicap International, 2004).

Mechanical assistive technology includes equipment such as manual wheelchair, postural management equipment, equipment for active exercise, protective devices, orthoses and aids for daily living. Provision of mechanical AT for children has its own unique challenges. Children are constantly changing as they grow and their abilities change and develop. Equipment therefore needs to be chosen with these aspects in mind. Adjustable equipment enables changes to be made according to a child's needs. Adjustability within a device does tend to make equipment heavier, more complex and expensive but it will last longer and may be adjusted to fit the constantly changing needs of a child (Cowan \& Wintergold, 2007).

The study of the influence of prenatal etiological factors on learning disabilities of children and adolescents with cerebral palsy in the Canton of Sarajevo was conducted with sample of 80 participants, children and adolescents with cerebral palsy in the Canton of Sarajevo, age from 6 up to 20 years; 25 children (age 6-11), and 75 adolescents (age 12-20). Mean age was 13,94 years, 47 male $(58,75 \%)$ and $33(41,25 \%)$ female. The sample was divided in two subgroups, first includes 30 participants whose mothers had problems during the pregnancy, and second includes 50 participants whose mothers didn't have problems during the pregnancy.

\begin{tabular}{|c|c|c|c|c|c|}
\hline \multirow[t]{2}{*}{ Cerebral palsy } & \multicolumn{4}{|c|}{ Walking ability } & \multirow[t]{2}{*}{ Total } \\
\hline & $\begin{array}{l}\text { Walks without } \\
\text { restrictions }\end{array}$ & Holding a hand & Walker & Wheelchair & \\
\hline \multicolumn{6}{|c|}{ Bilateral spastic CP } \\
\hline Spastic Quadriplegic CP & 2 & / & 1 & 10 & 13 \\
\hline Spastic Quadriplegic CP mixta & / & / & / & 3 & 3 \\
\hline Triplegia & / & / & / & 1 & 1 \\
\hline Paraplegia & 3 & 1 & 1 & 1 & 6 \\
\hline \multicolumn{6}{|c|}{ Unilateral spastic CP } \\
\hline Spastic Hemiplegic CP (right) & 5 & I & / & / & 5 \\
\hline Spastic Hemiplegic CP (left) & 4 & / & / & $/ 1$ & 5 \\
\hline Total & 14 & 1 & 2 & 16 & 33 \\
\hline
\end{tabular}

Table 1. Structure of the sample of children with CP and epilepsy according to walking ability (Švraka, 2012) 
Of 33 children with cerebral palsy and epilepsy, 14 (42,4\%) were able to walk independently, $1(3 \%)$ child needs to hold a mother's or friend's hand, $2(6 \%)$ children walks with assistive device (walker), and 16 (48,5\%) children were unable to walk, in need of wheelchair.

Of total sample of 80 participants, $34(42,5 \%)$ were in need of wheelchair, and $46(57,5 \%)$ were not.

Of total sample of 80 children, 42 (52,5\%) were able to walk independently.

In the group of 30 participants, with illnesses during pregnancy, $13(43,3 \%)$ were in need of wheelchair, and 17 (56,7\%) were not. In the group of 50 participants, without illnesses during pregnancy, 21 (42\%) were in need of wheelchair, and 29 (58\%) were not.

Of 30 participants with illnesses during pregnancy, 17 (56,7\%) were able to walk independently, and $13(43,3 \%)$ were not. Of 50 participants without illnesses during pregnancy, 25 $(50 \%)$, were able to walk independently, and 25 (50\%) were not.

\begin{tabular}{|c|c|c|c|c|}
\hline \multirow[t]{2}{*}{ Cerebral palsy } & \multicolumn{3}{|c|}{ Mobility assistance } & \multirow[t]{2}{*}{ Total } \\
\hline & Wheelchair & Without assistance & $\begin{array}{c}\text { Walker, tripod, } \\
\text { holding }\end{array}$ & \\
\hline \multicolumn{5}{|c|}{ Bilateral spastic CP } \\
\hline Spastic Quadriplegic CP & 7 & 2 & 0 & $9(30 \%)$ \\
\hline Spastic Quadriplegic CP mixta & 5 & 0 & 0 & $5(16,7 \%)$ \\
\hline Triparesis & 4 & 0 & 1 & $5(16,7 \%)$ \\
\hline Paraparesis & 3 & 3 & 2 & $8(26,7 \%)$ \\
\hline \multicolumn{5}{|c|}{ Unilateral spastic CP } \\
\hline Spastic Hemiplegic CP & 1 & 2 & 0 & $3(10 \%)$ \\
\hline Total & $20(66,7 \%)$ & $7(23,3 \%)$ & $3(10 \%)$ & $30(100 \%)$ \\
\hline
\end{tabular}

Table 2. Relation of cerebral palsy types and use of mobility assistance

Of 30 persons with cerebral palsy $20(66.7 \%)$ use wheelchairs, $7(23.3 \%)$ have independent mobility, without aid, and $3(10 \%)$ persons walk with aid. Client with triparesis use a walking tripod. 


\begin{tabular}{ccccc}
\hline Intellectual abilities & Mobility assistance & Total \\
\hline Normal intellectual abilities & 2 & Without assistance & $\begin{array}{c}\text { Walker, tripod, } \\
\text { holding }\end{array}$ \\
\hline Borderline intellectual abilities & 1 & 6 & 1 & $9(30 \%)$ \\
\hline Mild intellectual disability & 7 & 0 & 0 & $1(3,33 \%)$ \\
\hline Moderate intellectual disability & 1 & 0 & 1 & $7(23,3 \%)$ \\
\hline Severe intellectual disability & 7 & 1 & 0 & $3(10 \%)$ \\
\hline IQ not determined & 2 & 0 & 1 & $3(23,3 \%)$ \\
\hline Total & $20(66,7 \%)$ & $7(23,3 \%)$ & $3(10 \%)$ & $30(100 \%)$ \\
\hline
\end{tabular}

Table 3. Relation of intellectual abilities and use of mobility assistance

Of 7 persons with independent mobility, 6 are with normal intellectual abilities, and 1 with moderate disability. All seven persons (23.3\%) with severe intellectual disability use wheelchairs

The wheelchair and other wheeled seated mobility devices, such as scooters, have been and remain important technological devices in the field of rehabilitation. In North America, a substantial number of adults require wheeled seated mobility, with estimates indicating that over 179000 Canadians and over 1,5 million Americans utilize a wheelchair. With respect to the environment, wheeled seated mobility systems may increase the accessibility of the physical environment thereby increasing opportunities for interacting with the social environment (Reid, Laliberte-Rudman \& Hebert, 2002).

\section{Accessible home}

Accessibility for all is a fundamental right, and any environmental barrier which denies access and free movement for persons with disabilities and other persons with reduced mobility is and must be recognized as discrimination (Howitt, 2003).

An accessible home is a pre-condition for independent living or self-determined living as it enables individuals to do what they need and desire to do as independently as possible within their living space. This definition is addressed to all people meeting difficulties in performing daily activities at home as a result of a disability. It means that not only people with physical disabilities, people who we automatically have in mind when talking about accessibility, but also people with sensory or intellectual disabilities or even elderly people who might have lost certain capacities and therefore meet obstacles in their homes - all need accessible housing. For some, this can be achieved with accessible features that are permanently fixed such as wide doors, grab bars, a tub seat in the bathroom or by using adaptable features adjustable in a short time without involving structural or material changes. For 
individuals with sensory disabilities, a blind person, for instance, requires tactile markings for changes in the floor level and Braille markings on appliances. Individuals with hearing impairments will need visual adaptations for things such as telephone ringers, the doorbell and smoke alarms. For wheelchair users, access may require ramps at the entrances, lower counters, no thresholds, wider toilets, a shower rather than a bathtub, and ensuring there is an accessible lift if the dwelling is above the ground floor (Consumer's Guide to Accessible Housing, 2007).

Accessible living space is helping to enable an independent life and to provide way that people with disabilities live in the community. With personal assistant and accessible home, people with disabilities can live independently. Inadequate housing for people with disabilities has serious consequences. In the United Kingdom one study showed that there are over 4 million of people who have difficulties to move, but only 80000 are in accessible housing. Between 1980 and 1988 the number of homeless people with disabilities has increased by $92 \%$, not including those who live in institutions or family homes (Sestranetz, Adams, 2006).

Children with CP may have limitations in all areas of human occupation to some degree. Functional performance in self-care and independent living, school and work performance, play and recreation may all need to be addressed at some point in the child's life. Parents my require support and respite, as well as education, to care for child with CP to meet the needs of the family as a whole (Rogers, Gordon, Schanzenbacher, Case-Smith, 2001).

Another common problem people face in the region when adapting an inaccessible dwelling is that there are no services available to provide guidance and consultation on making the adaptations. In Calgary Canada, there is an Accessible Housing Society providing consultation services to people who wish to adapt their home. With this service, an occupational therapist and an architect visit individual homes to assess what needs to be adapted to suit the needs of the person and then draw up plans for modifications. They also provide information such as names of the relevant vendors and contractors, accessibility products and standards. There is no charge for the service if the client qualifies for income-tested government funding programs that include: Residential Access Modification Program, Residential Rehabilitation Assistance Program, Home Adaptations for Senior's Independence under the Alberta government housing support programs. Under these programs, applicants who qualify receive a grant to make proper adaptations. The government housing support programs contain an accessible housing registry for people seeking barrier-free dwellings. This registry refers clients to available accessible housing while documenting housing needs for future planning and construction (Disability Monitor Initiative South East Europe, 2007).

\subsection{Exterior accessibility}

The entrance should be well lighted and provide adequate cover from adverse weather conditions. If a ramp is to be installed, there should be adequate space. The recommended grade for wheelchair ramps is 12 inches in ramp length for every inch of threshold height. Ramps should be a minimum of 48 inches $(121,9 \mathrm{~cm})$ wide with a nonslip surface. Handrails also should be included on the ramp, 32 inches $(81,3 \mathrm{~cm})$ in height and extend 12 inches $(30,5 \mathrm{~cm})$ beyond the top and bottom of the ramp (Schmitz, 1988). 
Seven studies focused on aspects of the physical environment as it relates to accessibility issues and wheelchair accident. The most wheelchair accidents occur outdoors or on ramps. There remains a need for public buildings to implement barrier-free access changes for wheelchair users. Wheelchair users voiced concern about not being included in decisions regarding the design (Reid, Laliberte-Rudman \& Hebert, 2002).

For wheelchair users, the entrance should have a platform large enough to allow the patient to rest and to prepare for entry. This platform area is particularly important when a ramp is in use. The door locks should be accessible to the patient. The door handle should be turned easily by the person. The door should be open and close in a direction that is functional for the person. A cane may be hung outside the door to help the wheelchair user close the door when leaving. The doorway width should be measured. Generally, 32 inches $(81,3 \mathrm{~cm})$ to 34 inches $(86,3 \mathrm{~cm})$ is an acceptable doorway to accommodate most wheelchairs. (Schmitz, 1988).

\begin{tabular}{cccccccc}
\hline Place of living & \multicolumn{5}{c}{ Width of the entrance door (cm) } & Total \\
\hline & $\mathbf{6 2 - 7 5}$ & $\mathbf{7 6 - 8 2}$ & $\mathbf{8 3 - 9 2}$ & $\mathbf{9 3 - 1 0 2}$ & $\mathbf{1 0 3 - 1 1 2}$ & No answer \\
\hline Flat & 1 & 8 & 4 & - & 1 & 7 & $21(69,93 \%)$ \\
\hline Private house & 2 & 5 & 0 & - & - & 2 & $9(29,97 \%)$ \\
\hline Total & $3(9,99 \%)$ & $13(43,29 \%)$ & $4(13,32 \%)$ & 0 & $1(3,33 \%)$ & $9(29,97 \%)$ & $30(100 \%)$ \\
\hline
\end{tabular}

Table 4. Relations of the place of living and entrance door width

The range of width of the entrance door was from $62 \mathrm{~cm}$ to $112 \mathrm{~cm}$. Thirteen families $(43,29 \%)$ had entrance door width between $76 \mathrm{~cm}$ to $82 \mathrm{~cm}$.

\begin{tabular}{cccc}
\hline Place of living & Elevator & No & Total \\
\hline Flat & YES & 10 & $21(69,93 \%)$ \\
\hline Private house & 11 & 9 & $9(29,97 \%)$ \\
\hline Total & $11(36,63 \%)$ & $19(63,27 \%)$ & $30(100 \%)$ \\
\hline
\end{tabular}

Table 5. Place of living and existing of elevator

Eleven families $(36,63 \%)$ of persons with cerebral palsy, who live in flats have elevators. In private houses there are no elevators.

If there is raised threshold in the doorway, it should be removed. If removal is not possible, the threshold should be lowered to no greater than 0,5 inch $(1,27 \mathrm{~cm})$ in height, with beveled edges (Schmitz, 1988). 


\begin{tabular}{cccc}
\hline Threshold & \multicolumn{2}{c}{ Gender } & Total \\
\hline & Female & Male & \\
\hline Raised threshold & 14 & 9 & $23(76,7 \%)$ \\
\hline Without threshold & 2 & 5 & $7(23,3 \%)$ \\
\hline Total & $16(53,33 \%)$ & $14(46,67 \%)$ & $30(100 \%)$ \\
\hline
\end{tabular}

Table 6. Entrance door thresholds

Twenty three families $(76,7 \%)$ have raised entrance door thresholds made of different material: wood (16), concrete (3), metal (3), and one made of marble; $1 \mathrm{~cm}$ to $7 \mathrm{~cm}$ in height.

\subsection{Interior accessibility}

Inaccessible buildings and rooms crowded with furniture limit how children in wheelchairs move throughout the environment. Differences in the terrain or room surface also affect mobility. For example, a child who can run outdoors on an asphalt playground may trip and fall inside when walking on a rug. Other physical characteristics that the occupational therapist assesses relate to the type of furniture, objects, or assistive devices in the environment and whether they are usable and accessible. This includes the type of equipment, household items, clothing or toys. Sensory aspects of the physical environment often influence performance, e.g. the type of lighting, noise level, visual stimulation, and tactile or vestibular input of tasks (Shepherd, 2001).

Sufficient room should be made available for maneuvering or ambulating with an assistive device. Clear passage must be allowed from one room to the next. Unrestricted access should be provided to electrical outlets, telephones and wall switches. All floor coverings should be glued or tacked to the floor. This will prevent bunching or rippling under wheelchair use. Scatter rugs should be removed. Use of nonskid waxes should be encouraged. Raised thresholds should be removed to provide a flush, level surface. Doorways may need to be widened to allow clearance for a wheelchair or assistive device. Doors may have to be removed, reversed, or replaced with curtains or folding doors. All indoor stairwells should have handrails and should be well lighted. For patients with decreased visual acuity or agerelated visual changes, contrasting textures on the surface of the top and bottom stair/s will alert them that the end of the stairwells is near. Circular band or tape also can be placed at the top and bottom of the handrail for the same purpose (Schmitz, 1988).

\subsubsection{Bedroom}

The bed should be stationary and positioned to provide ample space for transfers. Stability may be improved by placing the bed against the wall or in the corner of the room. The height of the sleeping surface must be considered to facilitate transfer activities. The mattress should be carefully assessed; it should provide a firm, comfortable surface. If the mattress is in relatively good condition, a bed board inserted between the mattress and box spring may suffice to improve the sleeping surface adequately. If the mattress is badly worn, a new one 
should be suggested. A bed side table or cabinet might be suggested; it will be useful to hold a lamp, a telephone, necessary medications, and a call bell if assistance is needed (Schmitz, 1988).

\begin{tabular}{ccccccccccccccccc}
\hline Participants & \multicolumn{1}{c}{ Height of the bed (cm) } & & Total \\
\hline & 20 & 21 & 35 & 36 & 38 & 40 & 43 & 44 & 45 & 46 & 48 & 50 & 51 & 55 & 60 \\
\hline Children * & & & & & & 3 & 1 & & 2 & 2 & & 8 \\
\hline Adolescents & 1 & & 2 & 2 & 1 & 2 & & 3 & & 2 & 1 & 14 \\
\hline Adults & 1 & & 1 & & 2 & & 1 & & 1 & 1 & 1 & 8 \\
\hline Total & 1 & 1 & 2 & 3 & 1 & 7 & 1 & 1 & 3 & 2 & 1 & 4 & 1 & 1 & 1 & 30 \\
\hline
\end{tabular}

Children (4-11 years); Adolescents (12-20 years); Adults (21-53 years)

Table 7. Height of the bed and age of the participants

Range of the height of the bed was $20 \mathrm{~cm}$ to $60 \mathrm{~cm}$. The height of the bed of 7 participants was $40 \mathrm{~cm}$.

The range of the height of the bed of children was $40 \mathrm{~cm}$ to $50 \mathrm{~cm}$.

The range of the height of the bed of adolescents was $20 \mathrm{~cm}$ to $55 \mathrm{~cm}$.

The range of the height of the bed of adults was $21 \mathrm{~cm}$ to $60 \mathrm{~cm}$.

\begin{tabular}{|c|c|c|c|c|c|c|c|c|c|c|c|c|c|c|c|c|}
\hline \multirow[t]{2}{*}{ Participants } & \multicolumn{15}{|c|}{ Width of the bed $(\mathrm{cm})$} & \multirow[t]{2}{*}{ Total } \\
\hline & 55 & 65 & 68 & 80 & 90 & 95 & 100 & 105 & 110 & 120 & 125 & 150 & 162 & 170 & 220 & \\
\hline Children & 1 & 1 & & 1 & & & 2 & & 1 & 1 & & & 1 & & & 8 \\
\hline Adolescents & & & 1 & 3 & & 1 & 1 & 2 & 1 & 1 & 1 & 2 & & 1 & & 14 \\
\hline Adults & & & & & 2 & & 2 & & 1 & & & 2 & & & 1 & 8 \\
\hline Total & 1 & 1 & 1 & 4 & 2 & 1 & 5 & 2 & 3 & 2 & 1 & 4 & 1 & 1 & 1 & 30 \\
\hline
\end{tabular}

Table 8. Width of the bed and age of the participants

Range of the width of the bed was $55 \mathrm{~cm}$ to $220 \mathrm{~cm}$. The width of the bed of 5 participants was $100 \mathrm{~cm}$.

The range of the width of the bed of children was $55 \mathrm{~cm}$ to $162 \mathrm{~cm}$.

The range of the width of the bed of adolescents was $68 \mathrm{~cm}$ to $170 \mathrm{~cm}$.

The range of the width of the bed of adults was $90 \mathrm{~cm}$ to $220 \mathrm{~cm}$. 


\begin{tabular}{ccccc}
\hline Night table & Mobility assistance & Total \\
\hline Wheelchair & Without assistance & $\begin{array}{c}\text { Walker, tripod, } \\
\text { holding }\end{array}$ \\
\hline Without patient's reach & 6 & 4 & 0 & $10(33,3 \%)$ \\
\hline Without night table & 3 & 1 & 1 & $11(36,7 \%)$ \\
\hline Without answer & 2 & 2 & 0 & $7(23.3 \%)$ \\
\hline Total & $20(66,7 \%)$ & $7(23,3 \%)$ & $3(10 \%)$ & $30(100 \%)$ \\
\hline
\end{tabular}

Table 9. Relations of night table and mobility assistance

Of 30 persons with cerebral palsy, for $10(33,3 \%)$ persons night table is within patient's reach from bed, for 11 (36,7\%) persons night table is not within patient's reach from bed, 7 (23,3\%) persons don't have night table, and for two persons there are no answers.

Of 20 persons with wheelchair, for 6 persons night table is within patient's reach from bed, and for 9 persons night table is not within patient's reach from bed.

Of 7 persons with independent mobility, for 4 persons night table is within patient's reach from bed, for 1 person night table is not within patient's reach from bed, and 2 persons don't have night table.

\subsubsection{Bathroom}

If door frame prohibits passage of a wheelchair, the patient may transfer at the door to a chair with casters attached. An elevated toilet seat will facilitate transfer activities (Schmitz, 1988).

Special equipment that gives support can help the child feel safe and secure. Bath hammocks fully hold the body and enable the parent to wash the child thoroughly. A simple, inexpensive way for giving security is to use a plastic laundry basket lined with foam at its bottom. Commercially, alight, inconspicuous bath support offers good design features. The front half of the padded support ring swings open for easy entry and then locks securely, holding the child at the chest to give trunk stability. Various kinds of bath seats and shower benches are available for the older child to aid bathtub seating transfers. For the child with severe motor limitations who is lying supine in the tub in shallow water, a horseshoe-shaped inflatable bath collar serves to support the neck and keep the child's head above water level. A bath stretcher is constructed like a cot and fits inside the bathtub rim level or mid tub to minimize the caregiver's bending while transferring and bathing the child (Rogers, Gordon, Schanzenbacher, Case-Smith, 2001).

Independent toileting is an important self-maintenance milestone with wild variation among individual children. Independence in toileting includes getting on and off the toilet, managing fastener, and clothing, cleansings after toileting, and washing and drying hands effi- 
ciently without supervision. With weakness and limited range of motion, the child may be unable to manage fastenings because of hand involvement or may have problems in sitting down or getting up from the toilet seat because of hip-knee contractions or quadriceps weakness. (Shepherd, 2001).

\begin{tabular}{|c|c|c|c|c|}
\hline Cerebral palsy & Use of toilet seat & Use of toilet pot & Diapers & Total \\
\hline \multicolumn{5}{|c|}{ Bilateral spastic CP } \\
\hline Quadriplegic CP & 6 & 0 & 3 & 9 \\
\hline Quadripl. CP mixta & 1 & 1 & 3 & 5 \\
\hline Triparesis & 5 & 0 & 0 & 5 \\
\hline Paraparesis & 5 & 0 & 3 & 8 \\
\hline \multicolumn{5}{|c|}{ Unilateral spastic CP } \\
\hline Hemiplegic CP & 2 & 1 & 0 & 3 \\
\hline Total & $19(63,3 \%)$ & $2(6,7 \%)$ & $9(30 \%)$ & $30(100 \%)$ \\
\hline
\end{tabular}

Table 10. Use of toilet

Of total sample, $19(63,3 \%)$ patients use toilet seats, $2(6,7 \%)$ use toilet pot and nine $(30 \%)$ need diapers.

\begin{tabular}{|c|c|c|c|c|c|c|}
\hline \multirow[t]{2}{*}{ Cerebral palsy } & \multicolumn{2}{|c|}{ Window accessibility } & \multirow[t]{2}{*}{ No window } & \multirow{2}{*}{$\begin{array}{c}\text { No } \\
\text { bathroom }\end{array}$} & \multirow[t]{2}{*}{ No answer } & \multirow[t]{2}{*}{ Total } \\
\hline & YES & NO & & & & \\
\hline \multicolumn{7}{|c|}{ Bilateral spastic CP } \\
\hline Quadriplegic CP & 1 & 5 & 2 & 0 & 1 & 9 \\
\hline Quadripl. CP mixta & 0 & 5 & 0 & 0 & 0 & 5 \\
\hline Triparesis & 1 & 2 & 2 & 0 & 0 & 5 \\
\hline Paraparesis & 3 & 3 & 1 & 1 & 0 & 8 \\
\hline \multicolumn{7}{|c|}{ Unilateral spastic CP } \\
\hline Hemiplegic CP & 2 & 1 & 0 & 0 & 0 & 3 \\
\hline Total & $7(23,3 \%)$ & $16(53,3 \%)$ & $5(16,7 \%)$ & $1(3,33 \%)$ & $1(3,33 \%)$ & \\
\hline
\end{tabular}

Table 11. Window accessibility in the bathroom

Of 30 clients window in the bathroom is accessible for 7 (23,3\%), and not accessible for 16 clients. One family has no bathroom and five families have no windows in the bathroom. 
Grab bars (securely fastened to a reinforced wall) will assist in both toilet and tab transfers. Grab bars should be 1,5 inches $(3,8 \mathrm{~cm})$ in diameter and be knurled. For use in toilet transfers, the bars should be mounted horizontally 33 inches $(83,8 \mathrm{~cm})$ to 36 inches $(91,4 \mathrm{~cm})$ from the floor. The length of the grab bars should be between 24 inches $(61 \mathrm{~cm})$ and 36 inches $(91,4 \mathrm{~cm})$ on the back wall and 42 inches $(106,7 \mathrm{~cm})$ on the side wall. For use in tab transfers they should be mounted horizontally 24 inches $(61 \mathrm{~cm})$ high measured from the floor of the tub (Schmitz, 1988).

\begin{tabular}{|c|c|c|c|c|c|}
\hline \multirow[t]{2}{*}{ Cerebral palsy } & \multicolumn{2}{|c|}{ Toilet seats grab bars } & \multicolumn{2}{|c|}{ Bathing tab grab bars } & \multirow[t]{2}{*}{ Total } \\
\hline & YES & NO & YES & NO & \\
\hline \multicolumn{6}{|c|}{ Bilateral spastic CP } \\
\hline Quadriplegic CP & 1 & 8 & 1 & 8 & 9 \\
\hline Quadripl. CP mixta & 0 & 5 & 2 & 3 & 5 \\
\hline Triparesis & 1 & 4 & 1 & 4 & 5 \\
\hline Paraparesis & 1 & 7 & 1 & 7 & 8 \\
\hline \multicolumn{6}{|c|}{ Unilateral CP } \\
\hline Hemiplegic CP & 0 & 3 & 1 & 2 & 3 \\
\hline Total & $3(10 \%)$ & $27(90 \%)$ & $6(20 \%)$ & $24(80 \%)$ & $30(100 \%)$ \\
\hline
\end{tabular}

Table 12. Toilet seats and bathing tab grab bars

Of whole sample of 30 persons, 3 (10\%) patients have toilet seats equipped with grab bars, and $27(90 \%)$ patients do not have. Six (20\%) patients have bathing tab equipped with grab bars, and $24(80 \%)$ patients don't have.

\begin{tabular}{ccccccccc}
\hline Cerebral palsy & \multicolumn{3}{c}{ Toilet seat height (cm) } & & No answer & Total \\
\hline & $\mathbf{3 9}$ & $\mathbf{4 0}$ & $\mathbf{4 1}$ & $\mathbf{4 2}$ & $\mathbf{4 3}$ & $\mathbf{4 5}$ & \\
\hline & \multicolumn{7}{c}{ Bilateral spastic cerebral palsy } \\
\hline Quadriplegic CP & 1 & 4 & 2 & 1 & 1 & 0 & 0 & 9 \\
\hline Quadripl. CP mixta & 2 & 3 & 0 & 0 & 0 & 0 & 0 & 5 \\
\hline Triparesis & 1 & 2 & 0 & 2 & 0 & 0 & 0 & 5 \\
\hline Paraparesis & 3 & 2 & 2 & 1 & 0 & 0 & 0 & 8 \\
\hline Hemiplegic CP & 0 & 1 & 0 & 0 & 0 & 1 & 1 & 3 \\
\hline Total & 7 & 12 & 4 & 4 & $1(3,3 \%)$ & $1(3,3 \%)$ & 1 & 30 \\
& $(23,3 \%)$ & $(40 \%)$ & $(13,3 \%)$ & $(13,3 \%)$ & & $(3,3 \%)$ & $(100 \%)$ \\
\hline
\end{tabular}

Table 13. Range of toilet seat height 
Range of toilet seat height was $39 \mathrm{~cm}$ to $45 \mathrm{~cm}$. Toilet seat height for twelve clients (40\%) was $40 \mathrm{~cm}$, for $7(23,3 \%)$ was $39 \mathrm{~cm}$, for 4 clients $(13,3 \%)$ was $41 \mathrm{~cm}$, for other 4 was $42 \mathrm{~cm}$, for one $43 \mathrm{~cm}$ and for other one was $45 \mathrm{~cm}$.

\subsubsection{Kitchen}

The height of counter tops (work space) should be appropriate for the wheelchair user; the armrests should be able to fit under the working surface. The ideal height of counter surfaces should be no greater than 31 inches $(79 \mathrm{~cm})$ from the floor with a knee clearance of 27,5 inches $(69,8 \mathrm{~cm})$ to 30 inches $(76,2 \mathrm{~cm})$. Counter space should provide a depth of at least 24 inches $(61 \mathrm{~cm})$. All surfaces should be smooth to facilitate sliding of heavy items from one area to another. Slide out counter spaces are useful in providing an over-the-lap working surface. For ambulatory patients, stools (preferably with back and foot rests) may be placed strategically at the main work area/s (Schmitz, 1988).

\begin{tabular}{cccccc}
\hline Cerebral palsy & $\begin{array}{c}\text { Fitting of wheelchair in } \\
\text { the table }\end{array}$ & $\begin{array}{c}\text { Door } \\
\text { clearance }\end{array}$ & No answer & $\begin{array}{c}\text { Without } \\
\text { table }\end{array}$ & Total \\
\hline YES & NO & Bilateral spastic CP & & \\
\hline Spastic Quadriplegic CP & 3 & 3 & 0 & 1 & 7 \\
\hline Spastic Quadripl CP mixta & 4 & 0 & 0 & 0 & 5 \\
\hline Triparesis & 0 & 2 & 1 & 1 & 0 \\
\hline Paraparesis & 3 & 0 & 0 & 0 & 0 \\
\hline Spastic Hemiplegic CP & 0 & 1 & Unilateral spastic CP & & 3 \\
\hline Total & 10 & 6 & 0 & 0 & 0 \\
\hline
\end{tabular}

Table 14. Accessibility of kitchen table for patients in wheelchairs

Out of 20 persons in wheelchairs, for $10(50 \%)$ of them kitchen table is accessible. For 6 patients $(20 \%)$ with wheelchairs, kitchen table is inaccessible: wheelchairs do not fit in the table. One patient in wheelchair does not have a kitchen table, he has a dining room table (40 $\mathrm{cm}$ )which is inaccessible. Range of kitchen table height was from 45 up to $120 \mathrm{~cm}, 16$ different heights. Four (13.33\%) of patients don't have a kitchen table. Majority of patients, 5 $(16.7 \%)$ have a kitchen table which is $75 \mathrm{~cm}$ height. Thirteen persons have a kitchen table which is from 70 to $77 \mathrm{~cm}$ in height. 


\begin{tabular}{|c|c|c|c|c|c|}
\hline \multirow[t]{2}{*}{ CP } & \multicolumn{2}{|c|}{ Opening refrigerator } & \multirow[t]{2}{*}{$\begin{array}{l}\text { Without } \\
\text { refrigerator }\end{array}$} & \multirow[t]{2}{*}{ No answer } & \multirow[t]{2}{*}{ total } \\
\hline & YES & NO & & & \\
\hline \multicolumn{6}{|c|}{ Bilateral spastic CP } \\
\hline Quadriplegic CP & 4 & 5 & 0 & 0 & 9 \\
\hline Quadripl. CP mixta & 0 & 5 & 0 & 0 & 5 \\
\hline Triparesis & 3 & 2 & 0 & 0 & 5 \\
\hline Paraparesis & 5 & 3 & 0 & 0 & 8 \\
\hline \multicolumn{6}{|c|}{ Unilateral spastic CP } \\
\hline Hemiplegic CP & 2 & 1 & 0 & 0 & 3 \\
\hline Total & 14 & 16 & 0 & 0 & 30 \\
\hline
\end{tabular}

Table 15. Independent opening of the refrigerator and taking food

Refrigerator was accessible for 14 (46.7\%) clients, which can independently open the door and take food. Refrigerator was inaccessible for 16 (53.3\%) of clients. All clients have refrigerator.

\begin{tabular}{|c|c|c|c|c|c|}
\hline \multirow[t]{2}{*}{$\mathrm{CP}$} & \multicolumn{2}{|c|}{ Opening refrigerator } & \multirow{2}{*}{$\begin{array}{l}\text { Without } \\
\text { freezer }\end{array}$} & \multirow[t]{2}{*}{ No answer } & \multirow[t]{2}{*}{ total } \\
\hline & YES & NO & & & \\
\hline \multicolumn{6}{|c|}{ Bilateral spastic CP } \\
\hline Quadriplegic CP & 3 & 5 & 0 & 1 & 9 \\
\hline Quadripl. CP mixta & 0 & 4 & 0 & 1 & 5 \\
\hline Triparesis & 2 & 2 & 1 & 0 & 5 \\
\hline Paraparesis & 3 & 3 & 1 & 1 & 8 \\
\hline \multicolumn{6}{|c|}{ Unilateral spastic CP } \\
\hline Hemiplegic CP & 2 & 1 & 0 & 0 & 3 \\
\hline Total & 10 & 15 & 2 & 3 & 30 \\
\hline
\end{tabular}

Table 16. Independent opening of the freezer and taking food

Freezer was accessible for 10 (33.3\%) clients, which can independently open it and take food. Freezer was inaccessible for 15 (50\%) of clients. Two clients do not own a freezer, and three answers are omitted.

The sink may be equipped with large blade-tape handles, and a spray-hose fixture often provides improved function. Shallow sink 5 to 6 inches $(12,7 \mathrm{~cm}$ to $15,2 \mathrm{~cm})$ in depth will 
improve knee clearance below. As in the bathroom, hot-water pipes under the kitchen sink should be insulated to prevent burns (Schmitz, 1988).

\begin{tabular}{ccccccc}
\hline Cerebral palsy & $\begin{array}{c}\text { Fitting of wheelchair under } \\
\text { the sink }\end{array}$ & Door clearance & No answer Without sink & total \\
\hline YES & NO & Bilateral spastic CP & & \\
\hline Quadriplegic CP & 0 & 5 & 0 & 1 & 1 & 7 \\
\hline Quadripl. CP mixta & 1 & 3 & 0 & 1 & 0 & 4 \\
\hline Triparesis & 1 & 1 & 1 & 0 & 0 \\
\hline Paraparesis & 1 & 2 & 0 & 3 \\
\hline Hemiplegic CP & 0 & Unilateral spastic CP & 0 & 0 & 0 \\
\hline Total & 3 & 1 & 1 & 3 & 1 \\
\hline
\end{tabular}

Table 17. Sink accessibility for patients in wheelchairs

Of 20 persons in wheelchairs, kitchen sink is accessible for $3(15 \%)$ patients, or wheelchairs fit under the sink. For 12 patients $(60 \%)$ in wheelchairs, sink is inaccessible. One patient does not have a kitchen dink and for two there is no answer on this question.

Tap on the kitchen sink can open and close 15 (50\%) of clients. Kitchen sink tap is inaccessible for $12(40 \%)$ of patients. One patient does not have a kitchen dink and for one there is no answer. Kitchen sink bottom is accessible for 16 (53.3\%) of patients. Kitchen sink bottom is inaccessible for $11(36.7 \%)$ of patients.

\begin{tabular}{cccccc}
\hline Cerebral palsy & Opening/closing shelves & $\begin{array}{c}\text { Inaccessible } \\
\text { kitchen }\end{array}$ & No answer & No shelves & Total \\
\hline & YES & NO & Bilateral spastic CP & & \\
\hline Quadriplegic CP & 3 & 6 & 0 & 0 & 0 \\
\hline Quadripl. CP mixta & 2 & 3 & 0 & 0 & 5 \\
\hline Triparesis & 2 & 2 & 1 & 0 & 5 \\
\hline Paraparesis & 5 & 3 & 0 & 0 & 0 \\
\hline Hemiplegic CP & 2 & Unilateral spastic CP & 0 & 0 \\
\hline Total & 14 & 1 & 0 & 0 & 3 \\
\hline
\end{tabular}

Table 18. Shelves and cabinets accessibility in the kitchen for all patients 
Shelves and cabinets in the kitchen are accessible (opening and closing) for 14 patients $(46.7 \%)$, and inaccessible for $15(50 \%)$ of patients. For one patient kitchen is not accessible because is too narrow.

Equipment and food storage areas should be selected with optimum energy conservation in mind. All frequently used articles should be within easy reach, and unnecessary items should be eliminated. Additional storage space may be achieved by installation of open shelving or use of peg boards for pots and pans. If shelving is added, adjustable shelves are preferable and should be placed 16 inches $(41 \mathrm{~cm})$ above counter top (Schmitz, 1988).

\begin{tabular}{cccccc}
\hline Cerebral palsy & Transport possibility & Door clearance & No answer & Total \\
\hline & YES & NO & Bilateral spastic CP & & \\
\hline Quadriplegic CP & 3 & 6 & 0 & 0 & 5 \\
\hline Quadripl. CP mixta & 2 & 3 & 0 & 0 & 5 \\
\hline Triparesis & 1 & 3 & 1 & 1 & 8 \\
\hline Paraparesis & 4 & 3 & 0 & 0 \\
\hline Hemiplegic CP & 2 & Unilateral spastic CP & 1 & 3 \\
\hline Total & 12 & 1 & 1 & 30 \\
\hline
\end{tabular}

Table 19. Possibility to transport necessities (food, dishes...) around kitchen

$12(40 \%)$ of patients can carry necessities from one end of the kitchen to another, and 16 (53.3\%) cannot.

For 14 patients (46.7\%) inaccessible are stove switches, which means they cannot use them, and for $10(33.3 \%)$ are not. Four patients $(13.3 \%)$ do not use the kitchen, and two patients $(6.7 \%)$ did not give an answer.

Eleven patients $(36.7 \%)$ can operate stove doors, $12(40 \%)$ cannot, $4(13.3 \%)$ does not use the kitchen, and $3(10 \%)$ of patients did not answered

\section{Conclusion}

Based on the results of the evaluation with Environmental Assessment - Home assessment form, the study Occupation therapy for persons with cerebral palsy, in the Canton of Sarajevo, made proposals for changes in the environment to improve the accessibility of housing.

Educating persons with cerebral palsy and members of their families, with specific exercises to improve and preserve posture, balance, and coordination, increase the volume of mobility 
and prevent deformities deterioration, had an impact on the personal competencies, i.e. skills related to motor performance, sensor capabilities, cognitive ability and general health.

Private homes need to be converted according to the individual needs of tenants. As for the individual adaptation, arrangement of private space so that it is accessible, it requires precise planning according to the needs of people. Multidisciplinary team should lead that planning, and find such design solutions that overcome the problem of architectural barriers for people with disabilities to improve their quality of life.

Ideally, the physical and occupational therapists should accompany the patient on the home visit. They assume shared responsibility for assessing the patient's functional level at home. Depending of the specific needs of the patient and/or family, a speech therapist, social worker, or nurse also may be included on the home visit.

It is necessary to open the Services or Counseling centers for accessible housing. As part of these services, occupational therapist and an architect should visit homes of persons with disabilities and assess what needs to be adapted to meet the needs of that person.

The significance of this research for the community is multiple: educational, scientific, humane and promotional.

The results provide a basis for further research in needs of these families and improvement of their quality of life.

\section{Summary}

Accessible design generally refers to houses or other dwellings that meet specific requirements for accessibility. The laws dictate standards dimensions and characteristics for such features as door widths, clear space for wheelchair mobility, audible and visual signals, grab bars switch and outlet height, and more.

The research was conducted through Project: „Occupational therapy for persons with cerebral palsy", in homes of participants. The aim was to determine accessible housing for persons with cerebral palsy.

Sample was consisted of 30 respondents, members of the Association of persons with cerebral palsy of the Canton of Sarajevo, age from 4 up to 53: 8 children (4-11 years), 14 adolescents (12-20 years), and 8 adults (21-53 years); 14 male (46,67 \%) and 16 (53,33\%) female.

The principal measure used was the International Environmental Assessment - Home assessment form. The first part should deal with accessibility of the dwelling's exterior, and the second half should be concerned with an assessment of the home's interior. During the On-Site visit a tape measure and home assessment form are tools (Schmitz, 1988), translated and modified by the author (Švraka, 2007).

The Association of persons with cerebral palsy in the Canton of Sarajevo is member of Cerebral Palsy Association of Federation of Bosnia and Herzegovina which was established at 17. Oc- 
tober of 2011. That day was announced as Day of persons with cerebral palsy of Federation of Bosnia and Herzegovina (FB\&H). Cerebral Palsy Association members include five Associations of persons with cerebral palsy of FB\&H, from five towns/Cantons: Sarajevo, Goražde, Zenica, Široki Brijeg and Sapna.

Assistive devices include ortho-prosthetic devices, wheel chairs, walking aids, technical aids and adapted controls for cars. Adequate assistive devices are often financially inaccessible to many users because of their high cost despite the fact that they should be covered by social and insurance schemes. Under the current system, most assistive devices are covered only partially by the state and require user co-payments, which can be exorbitant in cost. Within the socialist system, assistive devices were generally provided for free within the public health care system. This is a crucial issue in South East Europe as one of the largest barriers to accessing assistive devices is financial.

Of 30 persons with cerebral palsy $20(66.7 \%)$ use wheelchairs, $7(23.3 \%)$ have independent mobility, and $3(10 \%)$ persons require the use of particular device. Client with triparetic $\mathrm{CP}$ use a walking tripod.

The range of width of the entrance door was from $62 \mathrm{~cm}$ to $112 \mathrm{~cm}$. Thirteen families $(43,29 \%)$ had entrance door width between $76 \mathrm{~cm}$ to $82 \mathrm{~cm}$.

Eleven families $(36,63 \%)$ of persons with cerebral palsy, who live in flats have elevators. In private houses there are no elevators.

Twenty three families $(76,7 \%)$ have raised entrance door thresholds made of different material: wood (16), concrete (3), metal (3), and one made of marble; $1 \mathrm{~cm}$ to $7 \mathrm{~cm}$ in height.

Of 30 persons with cerebral palsy, for $10(33,3 \%)$ persons night table is within patient's reach from bed, for $11(36,7 \%)$ persons night table is not within patient's reach from bed, $7(23,3 \%)$ persons don't have night table, and for two persons there are no answers.

Of total sample, $19(63,3 \%)$ patients use toilet seats, $2(6,7 \%)$ use toilet pot and nine $(30 \%)$ need diapers.

Of 30 persons window in the bathroom is accessible for $7(23,3 \%)$, and not accessible for 16 persons. One family has no bathroom and five families have no windows in the bathroom.

Of 30 persons, 3 (10\%) patients have toilet seats equipped with grab bars, and $27(90 \%)$ patients do not have. Six (20\%) patients have bathing tab equipped with grab bars, and 24 (80\%) patients don't have.

Range of toilet seat height was $39 \mathrm{~cm}$ to $45 \mathrm{~cm}$. Toilet seat height for $12(40 \%)$ persons was 40 $\mathrm{cm}$, for $7(23,3 \%)$ was $39 \mathrm{~cm}$, for $4(13,3 \%)$ persons was $41 \mathrm{~cm}$, for other 4 was $42 \mathrm{~cm}$, for one $43 \mathrm{~cm}$ and for other one was $45 \mathrm{~cm}$.

Three persons can enter the bathroom with wheelchairs. From whole sample, 3 (10 \%) persons have toilet seats equipped with grab bars, and 27 (90\%) persons do not have.

Out of 20 persons in wheelchairs, for $10(50 \%)$ of them kitchen table is accessible. For 6 patients $(20 \%)$ with wheelchairs, kitchen table is inaccessible: wheelchairs do not fit in the ta- 
ble. One patient in wheelchair does not have a kitchen table, he has a dining room table (40 $\mathrm{cm}$ )which is inaccessible. Range of kitchen table height was from 45 up to $120 \mathrm{~cm}, 16$ different heights. Four (13.33\%) of patients don't have a kitchen table. Majority of patients, 5 $(16.7 \%)$ have a kitchen table which is $75 \mathrm{~cm}$ height. Thirteen persons have a kitchen table which is from 70 to $77 \mathrm{~cm}$ in height.

Refrigerator was accessible for 14 (46.7\%) clients, which can independently open the door and take food. Refrigerator was inaccessible for 16 (53.3\%) of clients. All clients have refrigerator.

Freezer was accessible for 10 (33.3\%) clients, which can independently open it and take food. Freezer was inaccessible for $15(50 \%)$ of clients. Two clients do not own a freezer, and three answers are omitted.

Of 20 persons in wheelchairs, kitchen sink is accessible for $3(15 \%)$ patients, or wheelchairs fit under the sink. For 12 patients $(60 \%)$ in wheelchairs, sink is inaccessible. One patient does not have a kitchen dink and for two there is no answer on this question.

Tap on the kitchen sink can open and close 15 (50\%) of clients. Kitchen sink tap is inaccessible for $12(40 \%)$ of patients. One patient does not have a kitchen dink and for one there is no answer. Kitchen sink bottom is accessible for 16 (53.3\%) of patients. Kitchen sink bottom is inaccessible for $11(36.7 \%)$ of patients.

Shelves and cabinets in the kitchen are accessible (opening and closing) for 14 patients $(46.7 \%)$, and inaccessible for $15(50 \%)$ of patients. For one patient kitchen is not accessible because is too narrow.

$12(40 \%)$ of patients can carry necessities from one end of the kitchen to another, and 16 (53.3\%) cannot.

For 14 patients (46.7\%) inaccessible are stove switches, which means they cannot use them, and for $10(33.3 \%)$ are not. Four patients $(13.3 \%)$ do not use the kitchen, and two patients $(6.7 \%)$ did not give an answer.

Eleven patients (36.7\%) can operate stove doors, 12 (40\%) cannot, 4 (13.3\%) does not use the kitchen, and $3(10 \%)$ of patients did not answered

Ideally, the physical and occupational therapists should accompany the patient on the home visit. They assume shared responsibility for assessing the patient's functional level at home. Depending of the specific needs of the patient and/or family, a speech therapist, social worker, or nurse also may be included on the home visit.

It is necessary to open the Services or Counseling centers for accessible housing. As part of these services, occupational therapist and an architect should visit homes of persons with disabilities and assess what needs to be adapted to meet the needs of that person.

The results provide a basis for further research in needs of these families and improvement of their quality of life. 


\section{Acknowledgements}

I thank the children and families, members of the Association of persons with cerebral palsy of the Canton of Sarajevo, Bosnia and Herzegovina, who participated in this Project.

\section{Author details}

Emira Švraka

University of Sarajevo, Faculty of Health Studies in Sarajevo, Physiotherapy Department, Bosnia and Herzegovina

\section{References}

[1] Bottcher, L. (2010). Children with spastic cerebral palsy, their cognitive functioning, and social participation: a review. Child Neuropsychology, 16: 209-228.

[2] Carlsson, M.; Hagberg, G. and Olsson, I. (2003). Clinical aetiological aspects of epilepsy in children with cerebral palsy. Developmental Medicine \& Child Neurology 2003, 45: 371-376

[3] "Consumer's Guide to Accessible Housing" available at: http://www.abledata.com/ abledata_docs/icg-hous.htm In: Disability Monitor Initiative South East Europe. (2007) Free movement of people with disabilities in South East Europe.

[4] Cowan, D. and Wintergold, A. (2007). Assistive technology. In: Physiotherapy for Children. pp 139-160 Butterworth Heinemann Elsevier ISBN-13; 9780750688864

[5] Disability Monitor Initiative South East Europe (2007). Free movement of people with disabilities in South East Europe. An Inaccessible Right?

[6] Handicap International "Beyond De-Institutionalisation: The Unsteady Transition to an Enabling System in South East Europe", Disability Monitor Initiative (Belgrade: Handicap International: 2004): 58 In: Disability Monitor Initiative South East Europe. (2007) Free movement of people with disabilities in South East Europe.

[7] Howitt, R. (2003). Member of European Parliament, President of the Disability Intergroup of the European Parliament. In: Disability Monitor Initiative South East Europe. (2007) Free movement of people with disabilities in South East Europe.

[8] Jacobsson, B. and Hagberg, G. (2004). Antenatal riscs factors for cerebral palsy. Best Pract Clinic Obstetric Gynaecol, 18 (3), 425-436 
[9] Loga, S. (2011) Transition of Bosnian-Herzegovinian society and its impact on health protection. University of Sarajevo. International symposium. Proceedings: Bosnia and Herzegovina - 15 years of Dayton peace agreement. pp 225-241

[10] Nordmark, E.; Hagglund, G. \& Lagergren, J. (2001). Cerebral Palsy in south Sweden. Prevalence and clinical features. Acta Pediatrica 90: 1271-1276

[11] Odding, E.; Roebroeck, M. E. \& Stam, H. J. (2006). The epidemiology of cerebral palsy: Incidence, impairments and risk factors. Disability and Rehabilitation, 28(4): 183-191.

[12] Parkes, J.; White-Koning, M.; O Dickinson, H.; Thyen, U.; Arnaud, C.; Beckung, E. \& all. (2008). Psychological problems in children with cerebral palsy: a cross-sectional European study. The Journal of Child Psychology and Psychiatry 49: 4, p. 405-413.

[13] Reid, D.; Laliberte-Rudman, D. \& Hebert, D. (2002) Impact of wheeled seated mobility devices on adult users' and their caregivers' occupational performance: A critical literature review. Canadian Journal of Occupational Therapy. Volume 69, Number 5, pp 261-281 ISSN-0008-4174

[14] Rogers, S. L.; Gordon, C. Y.; Schanzenbacher, K. E.; Case-Smith, J. (2001) In: CaseSmith J. Occupational Therapy for Children, fourth edition. Mosby. An Affiliate of Elsevier Science. St Louis, London, Philadelphia, Sydney, Toronto. ISBN 0-323-00764-3

[15] Schmitz, T. J. (1988) Chapter 13: Environmental assessment. In: Physical rehabilitation: Assessment and treatment. Second edition. pp. 237- 251 ISBN 0-8036-6698-5

[16] Sestranetz, R. \& Adams, L. (2006) In: Disability Monitor Initiative South East Europe. (2007) Free movement of people with disabilities in South East Europe.

[17] Shepherd, J. (2001) Self-Care and Adaptations for Independent Living. In: CaseSmith J. Occupational Therapy for Children, fourth edition. Mosby. An Affiliate of Elsevier Science. St Louis, London, Philadelphia, Sydney, Toronto. ISBN 0-323-00764-3

[18] Stiers, P. \& Vanderkelen, R. (2002). Visual-perceptual impairment in a random sample of children with cerebral palsy. Developmental Medicine $\mathcal{E}$ Child Neurology, 44: 370-382.

[19] Švraka, E. (2007) Another side of life - Learning difficulties of children with cerebral palsy. Second enlarged edition. TDP d.o.o. Sarajevo ISBN 978-9958-9214-7-6

[20] Švraka, E.; Loga, S.; Brown I. (2011) Family quality of life: adult school children with intellectual disabilities. Journal of Intellectual Disability Research 55, pp 1115-1122.

[21] Švraka, E. (2012) Chapter: Children with cerebral palsy and epilepsy. In: EpilepsyHistological, Electroencephalographic and Psychological Aspects. Edited by Dejan Stevanovic p. 251-276 INTECH Open Access Publisher of Scientific Books and Journals ISBN 978-953-51-0082-9 Printed in Croatia www.intechopen.com 